\title{
O GRÉMIO DO COMÉRCIO DO CONCELHO DE GUIMARÃES: DINÂMICAS CORPORATIVAS, ASSOCIATIVAS E COMERCIAIS
}

\author{
THE TRADE GUILD OF THE MUNICIPALITY OF GUIMARÃES: \\ CORPORATE, ASSOCIATIVE AND COMMERCIAL DYNAMICS
}

DOI: http//dx.doi.org/10.15448/21778-3748.2018.2.26573

Jorge Mano Torres

Doutorando em História - Universidade Nova de Lisboa jorgemanotorres@hotmail.com

\begin{abstract}
RESUMO: Este artigo procura demonstrar a realidade do Grémio do Comércio do Concelho de Guimarães, organismo primário da organização corporativa estabelecida pelo Estado Novo, entre o ano de sua emergência, em 1939, e a sua extinção, em 1975, com base na documentação que sobreviveu à sua extinção. O objetivo é analisar este organismo, em particular no que se refere às dinâmicas corporativa e interna da organização, bem como às relações com entidades fora da organização corporativa, com base na exploração das atas de seus órgãos de administração. Finalmente, caracteriza-se o universo social dos membros, levando em consideração o setor de atividade, a dimensão da empresa e sua localização no território vimaranense.
\end{abstract}

PALAVRAS-CHAVE: Portugal; Estado Novo; Corporativismo; Grémios do Comércio.

\begin{abstract}
The present paper seeks to demonstrate the reality of the Trade Guild of Guimarães, a primary agency of the corporate organization established by the Estado Novo, between the year of its emergence in 1939 and its extinction, in 1975, based on the documentation that survived its extinction. The objective is the analysis of this body, regarding the corporate and internal dynamics of the organization, as well as relations with entities outside the corporate organization, based on the investigation of the minutes of its governing agencies. Finally, its associates' social universe is characterized considering the sector of activity, the size of the company and its location in the territory of the Guimarães county.
\end{abstract}

KEYWORDS: Portugal; Estado Novo; Corporatism; Trade Guilds.

\section{O ESTADO NOVO E O CORPORATIVISMO}

A Constituição de 1933, o pilar fundador do regime, proclama uma república unitária e corporativa entre princípios liberais e corporativos. O corporativismo, como ideologia e instrumento de controle e disciplina social do movimento trabalhista e sindical e "principal quadro orgânico de regulação e equilíbrio entre os diversos sectores da classe dominante (ROSAS, 2013, p. 281)" é um dos principais fatores de longevidade política do Estado Novo. 
O corporativismo português aparece enquadrado em uma vaga corporativa onde se destacam os casos da Itália de Mussolini e da Espanha de Franco. O corporativismo italiano que não era uma distância irremediável e profunda entre projetos e realizações, mas uma possível versão de atuação (GAGLIARDI, 2010) - serve como inspiração para as ditaduras corporativas [ibéricas e latinas], se distinguindo o corporativismo português dessas formas de corporativismo pelo próprio Estatuto do Trabalho Nacional e também pela organização corporativa do trabalho.

O Corporativismo surge como uma resposta à crise do capitalismo e à ameaça comunista, defendendo um "sistema capitalista organizado e coordenado pelo próprio Estado" (GARRIDO, 2012, p.146).

Como primeiro-ministro, Salazar lançou a reestruturação corporativa da vida política, econômica e social nacional, com a Constituição de 1933 constituindo uma das mais importantes instituições criadas, uma vez que prevê uma Câmara Corporativa com representatividade orgânica; junto com o Conselho de Estado (órgão consultivo de alto nível também com representatividade orgânica); do Conselho Corporativo (centro de coordenação do regime); o Estatuto do Trabalho Nacional (regulador das relações entre trabalho e capital); e o Subsecretariado de Estado das Corporações e Previdência Social. No momento da aprovação do ETN, foram publicados os cinco decretos que lançaram a base da organização corporativa - grémios, sindicatos, casas do povo e casas dos pescadores - com o lançamento desses organismos a ser acompanhado ou precedido de decretos e ações governamentais que eliminaram as organizações não corporativas já existentes. Mais de 20 anos depois surgem as corporações, o topo da pirâmide corporativa, que deveria integrar capital e mão-de-obra, formando grandes organizações que participariam das orientações políticas econômicas e sociais.

O modelo corporativo impõe um sistema de valores que interfere com a organização da vida econômica e, mais do que com o sistema, é organização. Tendo sido definido como um instrumento para a prevenção de conflitos sociais, essa concepção nunca foi corrigida. Assim, é uma maneira de disciplinar o capital e o trabalho, buscando alcançar "objetivos de equilíbrio e harmonia social" (CARDOSO, 2012, p., 102), subjugando os interesses econômicos aos interesses nacionais, tornando-o um poderoso instrumento do Estado sobre a sociedade. Os ideais de cooperação e solidariedade para a sociedade e a nação se sobrepõem aos valores individuais e ao indivíduo. A sociedade orgânica congrega harmoniosamente famílias, paróquias, municípios e corporações como um todo coeso e articulado de acordo com as orientações e diretrizes do Estado (LUCENA, 1976; ROSAS, GARRIDO, 2012). 


\section{GRÉMIOS DO COMÉRCIO: QUADRO NORMATIVO E TIPOLOGIA}

Desta forma, todas as entidades patronais foram forçadas a se organizar corporativamente, através da criação de grémios. Esses agrupavam empresas, sociedades ou firmas ( singulares ou coletivas) dedicadas a qualquer dos setores da atividade econômica. Como personalidades jurídicas, os grémios "representam legalmente todos os elementos do mesmo ramo de comércio, indústria ou agricultura [...] tutelam os seus interesses perante o Estado e os outros organismos corporativos; ajustam com os sindicatos nacionais contratos coletivos de trabalho"1. Por sua vez, a lei consagra as obrigações dos grémios, como a emissão de pareceres sobre o setor de atividade ou assuntos relacionados (como questões de higiene e segurança no trabalho $)^{2}$. Eles também têm a obrigação de criar instituições sindicais de previdência em conjunto com os sindicatos nacionais.

Uma breve análise do Decreto-Lei n. ${ }^{\circ} 23049$ sugere que a legislação promulgada age em defesa dos interesses do Estado (especialmente os interesses econômicos e sociais), reprimindo, ao mesmo tempo, os interesses de associação e subjugando-os ao propósito político. Em qualquer caso, o diploma permite ainda a sobrevivência de muitas associações comerciais, admitindo que sejam reguladas pelos estatutos vigentes, mesmo que de forma provisória.

Cinco anos depois, a publicação de um novo decreto legislativo é decisiva para a extinção das associações comerciais e a sua conversão obrigatória à estrutura gremial (DecretoLei n. ${ }^{\circ} 29232$, de 8 de dezembro de 1938). Este diploma surge com o objetivo de regular a integração das associações patronais estabelecidas no âmbito do decreto de 9 de maio de 1891 na organização corporativa, devido à impossibilidade de associações com estrutura homogênea - associações comerciais e industriais, como é o caso de Guimarães - de integrar a organização corporativa mantendo a mesma estrutura, exigindo que essas associações abandonem um dos ramos da atividade.

O decreto de 1938 regula a constituição e a natureza dos grémios. Assim, as associações que agrupam empresas que estão ligadas ao mesmo setor de atividade (comércio ou indústria), e que ainda não se encontrassem organizadas corporativamente, podiam ser transformadas em grémios distritais ou concelhios (art. 2. ${ }^{\circ}$ ). Por outro lado, as associações que reunissem empresas atuando em diferentes setores econômicos podiam se em uniões de grémios, desde

\footnotetext{
${ }^{1}$ DECRETO-LEI n. ${ }^{\circ} 23049$ de 23 de setembro de 1933, art. 6. ${ }^{\circ}$.

${ }^{2}$ DECRETO-LEI n. ${ }^{\circ} 23049$ de 23 de setembro de 1933, art. 8. ${ }^{\circ}$.
} 
que existisse "devida afinidade"3 entre essas empresas, ou podiam solicitar a criação de grémios de acordo com os diferentes ramos de atividade ( $\operatorname{art}^{\circ} 3 .^{\circ}$ ).

Os grémios constituídos sob este Decreto-Lei n. ${ }^{\circ} 29232$ estavam sujeitos ao regime legal estabelecido em lei anterior, no âmbito do Decreto-Lei n. ${ }^{\circ} 24715$, de 3 de dezembro de 1934. Nestas circunstâncias, define-se o quadro normativo que passa pela elaboração de novos estatutos, até 30 de junho de 1939, a serem submetidos à aprovação do subsecretário de Estado das Corporações e Previdência Social, sob pena de dissolução ${ }^{4}$. Os estatutos dos grémios deviam estar em harmonia com as disposições do Estatuto do Trabalho Nacional e a legislação complementar 5 .

\section{A IMPLANTAÇÃO DOS GRÉMIOS DO COMÉRCIO A NÍVEL NACIONAL}

A legislação aprovada, previa a criação de quatro tipos de grémios do comércio, no âmbito da estrutura corporativa: varejista misto; varejista diferenciado; de exportação; e de armazenistas e importação.

De acordo com o quadro da pesquisa realizada sobre a organização e distribuição destes organismos no território nacional - que nos dá a conhecer a amplitude da rede de grémios comerciais e em simultâneo contextualiza o estudo de caso que se apresenta sobre o Grémio do Comércio de Guimarães - contabilizam-se 225 organismos, recenseados em Portugal Continental e nas regiões autónomas (Açores e Madeira): 99 retalhistas mistos; 94 retalhistas diferenciados; 14 de exportação; e 18 de armazenista e importação (contando-se ainda 14 federações e seis uniões).

De acordo com o quadro da pesquisa realizada sobre a organização e distribuição destes organismos no território nacional - o que nos dá a amplitude da rede de grémios comerciais e, ao mesmo tempo, contextualiza o estudo de caso que é sobre o Grémio do Comércio de

\footnotetext{
${ }^{3}$ Decreto-Lei n. ${ }^{\circ} 29232$ de 8 de dezembro de 1938, artigo 3.o. Por afinidade entende-se o objeto das atividades exercidas, mas também o grau de seu comércio, considerando-se distintos os comerciantes que vendem a retalho ou por grosso. Ainda assim, existe uma exceção que define que "onde o comércio de retalho se exerça normalmente por forma mista e se não justifique a aprovação de uniões poderão as respectivas associações transformar-se em grémios distritais ou concelhos".

${ }^{4}$ As associações de classe patronais de atividade comercial ou industrial já organizadas corporativamente eram imediatamente dissolvidas [DECRETO-LEI n. ${ }^{\circ} 29232$, art. $8^{\circ}{ }^{\circ}$.

${ }^{5}$ Ver os conteúdos e itens a incluir necessariamente nos estatutos de acordo com o Decreto-Lei n. ${ }^{\circ} 24715$, ou seja, a denominação do grémio, a localização da sede, atribuições e propósitos, bem como os deveres e obrigações, que incluem algumas declarações que concorrem abertamente pela ideologia do regime. Entre outros, vale a pena notar o reconhecimento dos princípios e propósitos da coletividade nacional e o repúdio de todas e quaisquer atividades contrárias aos interesses da nação portuguesa; o reconhecimento da constituição do grémio como fator de cooperação ativa com todos os outros elementos da economia nacional; os procedimentos e condições de admissão de sócios.
} 
Guimarães - existem 225 organismos registrados em Portugal Continental e nas regiões autónomas (Açores e Madeira): 99 varejistas mistos; 94 varejistas diferenciados; 14 de exportação; e 18 de armazenista e importação (contando ainda 14 federações e seis uniões).

Os grémios de comércio varejista misto tinham configurações espacial-administrativas particulares, nomeadamente: organismos concelhios, organismos pluriconcelhios e organismos distritais: os primeiros representam $65 \%$, os pluriconcelhios $27 \%$, e os distritais apenas $8 \%$.

Os primeiros grémios de comércio varejista misto apareceram em 1939 - Guimarães, Viana do Castelo, Ponte de Lima, Matosinhos, Guarda, Leiria e Setúbal. No entanto, é na década de 1940 que esses organismos se espalharam: entre 1940 e 1944, 79 desses organismos foram criados; na década de 1950 são criados seis novos grémios; e, entre 1960 e 1970, surgem os últimos sete grémios de varejo misto.

Vale a pena notar que a estrutura orgânica dos grémios de comércio varejista misto de Amarante, Felgueiras, Peniche e Pombal são criadas no momento da instituição do grémio, ao contrário da maioria dos casos iniciais, ou de Vila Nova de Famalicão, cuja estrutura é criada dois anos depois da extinção da associação comercial local.

Os grémios de comércio de varejo diferenciado diferem em sua escala espacialadministrativa em relação aos grémios de comércio varejistas mistos. A maioria deles (74 de 94) está concentrada em três municípios: Porto, Lisboa e Coimbra ${ }^{6}$, onde estão registradas as três uniões de grémios de lojistas/comerciantes. Existiam também cinco grémios distritais, 11 grémios regionais - Norte, Centro e Sul - e quatro grémios nacionais.

A distribuição em uma escala de tempo tem semelhanças com o caso dos grémios varejistas mistos: embora os grémios varejistas diferenciados tenham emergido anteriormente aos varejistas mistos (os primeiros nove são criados entre 1936 e 1939), é na década de 1940 que sua distribuição é mais intensa, com a criação de 75 grémios; entre 1956 e 1963 emergem oito novos organismos e, finalmente, em 1971-1972, foram criados dois novos grémios.

"Num segundo nível, estes organismos [grémios do comércio] podiam constituir, de acordo com o respectivo modelo institucional, federações ou uniões" (FREIRE, ESTEVÃO FERREIRA, RODRIGUES, 2014, p. 7). Já uniões são três - surgidas em 1940 - nos concelhos de Lisboa, Porto e Coimbra.

Existiam nove federações dos grémios de comércio varejista misto, que cobriam quase todo o território continental, distribuídas igualmente em termos do espaço administrativo do

\footnotetext{
${ }^{6}$ Estes conselhos gozam de um estatuto especial, mantendo suas respectivas associações comerciais, que não são extintas (ao contrário do resto do país).
} 
país: cinco distritais (Aveiro, Faro, Leiria, Lisboa e Santarém) e quatro regionais (Minho, Alentejo e zonas das Beiras), todos criados no espaço de um ano, entre o final de 1958 e o final de 1959. Existiam ainda três uniões - fundadas em 1940 - nos municípios de Lisboa, Porto e Coimbra.

\section{A InStituiçÃo dO GRÉMIO dO COMÉRCIO DO CONCELHO DE GUIMARÃES}

Em 25 de maio de 1939, a administração da Associação Comercial e Industrial de Guimarães (ACIG) - uma associação que remontava a 1865 - reuniu em sessão extraordinária, na sequência de uma reunião dos credores que tinham subscrito a compra do edifício sede, e anunciou aos sócios a realização de uma reunião, daí para 30 dias, com o objetivo de transformá-la em um grémio do comércio. Em 30 de junho, ocorreu a última reunião da ACIG que marca também o fim de sua atividade, após 74 anos de existência. A conversão do organismo se enquadra "na evolução social do País que preconizava quadros económicos modelados sob concepções de novo carácter, a coletividade ia transformar-se em grémio patronal, aderindo assim à estrutura do Estado Corporativo saído da Revolução de 28 de maio" (BASTOS, 1957, p. 52).

Em 31 de julho de 1939, ocorreu a primeira reunião do Comitê Organizador do Grémio do Comércio (composta por membros das extintas ACIG e da Associação Comercial de Revendedores de Vinhos e Víveres). Seguindo os procedimentos, o comitê organizador do GCCG inicia os procedimentos legais que passam pela elaboração do projeto de estatutos, enquadrados nos fundamentos da organização corporativa. Os estatutos são aprovados por alvará do Subsecretário de Estado das Corporações e Previdência Social, de 20 de abril de 1940, que cria oficialmente o GCCG, de acordo com o estatuto de grémio concelhio de comércio misto.

O GCCG foi o primeiro a ser criado no distrito de Braga. Em 1940 foram estabelecidos os Grémios do Comércio dos municípios de Braga, Barcelos e Esposende e, em 1941, é criado o Grémio do Comércio de Vila Nova de Famalicão. Em breve, alguns sofrem mudanças que envolvem a integração de mais de um município. É o que acontece, em particular, com o Grémio de Fafe, que vem a integrar os municípios de Cabeceiras e Celorico de Basto, e com o Grémio de Braga, que abrangerá os municípios de Amares, Póvoa de Lanhoso, Terras de Bouro, Vieira do Minho e Vila Verde, em 1943 e 1945, respectivamente. Esta mudança também está prevista para o GCCG, que estenderia sua área administrativa para os municípios de Póvoa de Lanhoso 
e Vieira do Minho, no entanto, a vontade dos comerciantes desses conselhos acaba ditando sua integração no Grémio bracarense.

A conversão da ACIG em GCCG implicou mudanças substanciais, visíveis nos novos estatutos do organismo. Estes são emblemáticos dos fundamentos formativos do Estado Novo na organização e regulação das atividades econômicas. Os objetivos da instituição gremial consistiam na disciplina das atividades comerciais e no repúdio à luta de classes e na predominância das plutocracias (art. ${ }^{\circ} 4^{\circ}$ ) - em vez do destaque anteriormente atribuído aos interesses do comércio e ao desenvolvimento da região e dos associados. As competências do GCCG estão subordinadas à organização corporativa, em articulação direta com os órgãos corporativos superiores ou do Estado e de acordo com o Regimento das Corporações (art. 6. ${ }^{\circ}$ ).

As mudanças em termos orgânicos institucionais também são notórias. A antiga Assembleia Geral, que correspondia ao poder supremo da entidade, liderada pelos sócios, perde esse estatuto e constitui apenas, de acordo com o artigo $5^{\circ}$ dos Estatutos, uma "reunião dos sócios no pleno gozo dos seus direitos" (GCCG, 1940, p.11). O número de reuniões diminui significativamente: de duas sessões anuais, de acordo com os Estatutos de 1925, a periodicidade se torna bienal. Da mesma forma, as competências e funções dos órgãos diretivos registram mudanças relacionadas com a extinção da dinâmica participativa dos sócios nas deliberações do organismo, que redundam em seu relativo vazamento. Em contrapartida, é criado o Conselho Geral que absorve parte das competências da antiga AG. Por sua vez, a direção é reduzida para três elementos e começa a desempenhar o papel mais ativo na consolidação e liderança do organismo (art. ${ }^{\circ} 24 .^{\circ}$ ). A enumeração das competências atribuídas sinaliza a materialização da orgânica corporativa que passa, entre outras atribuições, pela harmonização de acordos coletivos e acordos trabalhistas e outros compromissos corporativos; pela organização dos grupos comerciais de acordo com o universo dos sócios; e pela elaboração anual da lista de sócios.

O sistema de admissão dos sócios tornou-se aparentemente mais simples: deixa formalmente de ser exigida a boa reputação moral e civil do candidato para a adesão, bem como a maioridade ou equivalente legal. $\mathrm{O}$ estatuto de sócio efetivo implica ser um proprietário de um estabelecimento e estar coletado para efeitos de contribuição industrial. Os sócios auxiliares, admitidos diretamente pela direção, acabam desaparecendo após despacho do subsecretário de Estado das Corporações e Previdência Social. Registro ainda, nesta breve incursão sobre os Estatutos de 1940, as situações de dependência efetiva a órgãos superiores da 
estrutura corporativa, para fins de aprovação de órgãos administrativos eleitos, nomeações de comissões, entre outras, indicador da total subordinação aos ditames do sistema.

A área do município de Guimarães na época corresponde à área administrativa abrangida pelo GCCG, que compreende um total de 73 freguesias e uma área de aproximadamente $256,05 \mathrm{~km} 2$ - dos quais apenas cerca de $1,43 \mathrm{~km} 2$ correspondem à área urbana - existente Três paróquias urbanas e 70 paróquias rurais.

A área do município de Guimarães na época corresponde à área administrativa abrangida pelo GCCG, que compreende um total de 73 freguesias e uma área de aproximadamente $256,05 \mathrm{~km} 2$ - dos quais apenas cerca de 1,43 km2 correspondem à área urbana - existindo três freguesias urbanas e 70 rurais $^{7}$.

Mapa I - Mapa do concelho de Guimarães entre 1939 e 1970

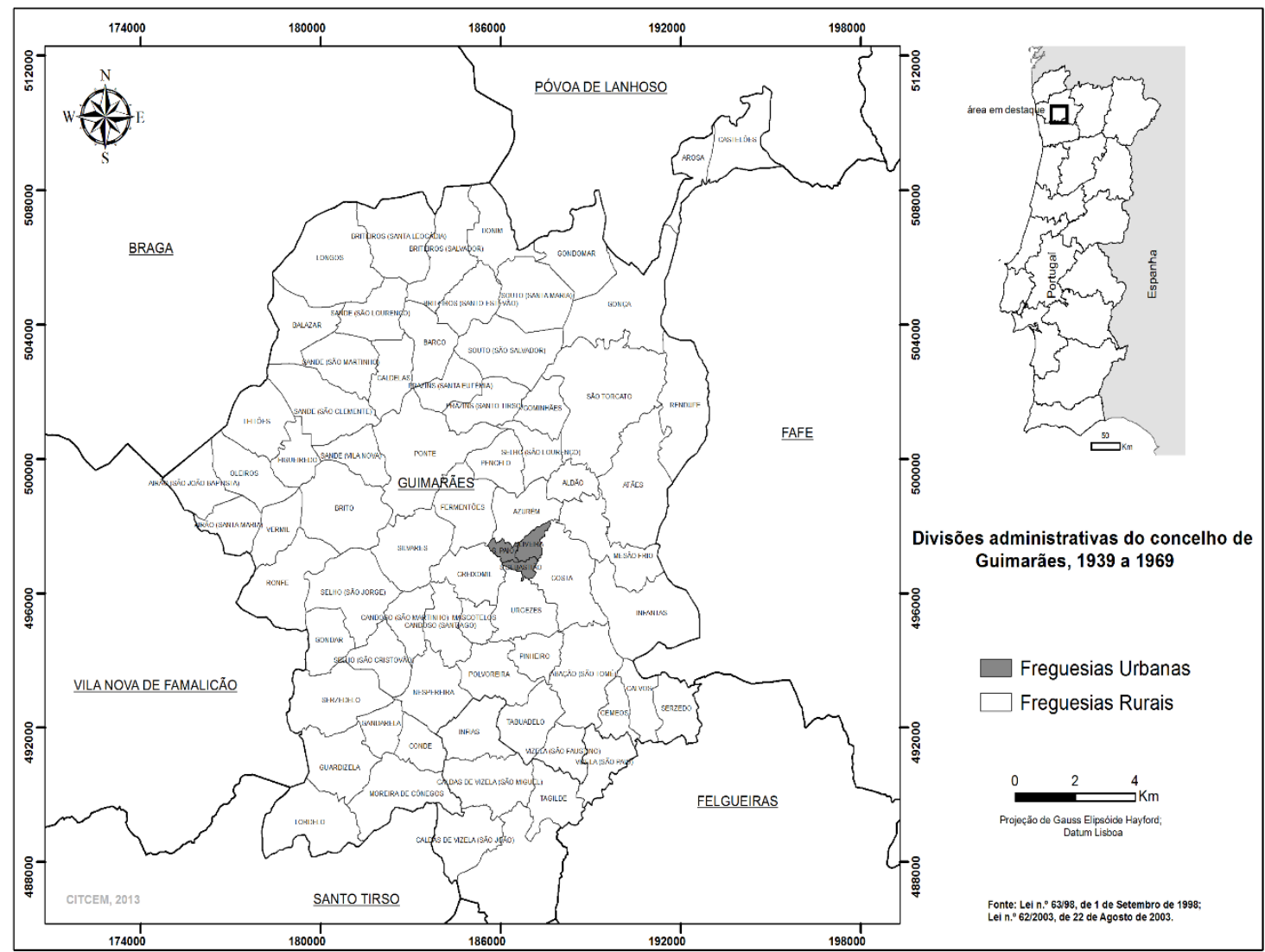

Demograficamente, o município de Guimarães apresenta um total de 418175 habitantes na soma dos censos entre 1940 e 1970, registando um aumento gradual entre todos os censos,

\footnotetext{
7 A Lei n. ${ }^{\text {o }}$ 63/98, de 1 de setembro de 1998, cria o concelho de Vizela, que absorve cinco freguesias nomeadamente, São João das Caldas de Vizela, São Miguel das Caldas de Vizela, São Paio de Vizela, Infias e Tagilde que, à época em estudo, se encontram integradas no concelho de Guimarães.
}

Oficina do Historiador, Porto Alegre, EDIPUCRS, v. 11, n. 2, jul./dez. 2018, 
seguindo a tendência nacional - pelo menos até a década de 60 - enquadrada no crescimento da população portuguesa verificado nas duas décadas anteriores, em consequência, de acordo com Fernando Rosas, de uma série de condições favoráveis: melhoria das condições higiênicosanitárias e de vida em geral; queda da mortalidade; aumento da taxa de nupcialidade (associada a uma diminuição da idade média do casamento, o que levou a um aumento do período de vida fértil das mulheres); redução da emigração.

O ambiente rural surge como mais proeminente em relação ao ambiente urbano, com um maior número de moradores: em 1940 há 70784 residentes em áreas rurais, 14624 famílias e 13682 casas; no mesmo ano, havia 11336 residentes, 2245 famílias e 1554 casas, uma pequena fração da população rural (14\% dos residentes, 13\% das famílias e 10\% das casas). Esta situação é explicada pelas dimensões das áreas ocupadas pelos dois meios, o que justifica que quando a densidade populacional é analisada, o panorama mude dramaticamente, com o ambiente urbano emergindo com maior destaque: em 1940, o meio rural tem uma densidade populacional de 277, 9 hab/ $\mathrm{km}^{2}$; já o ambiente urbano apresenta uma densidade de 7927,2 hab $/ \mathrm{km}^{2}$. Convertendo esses números em porcentagens, o meio rural representa $82 \%$ de todos os habitantes do município; já a taxa de densidade populacional é de $97 \%$ - 3\%, a favor do ambiente urbano, uma tendência que, além disso, é seguida em relação às famílias e às habitações do município. Assim, apesar do grande número de habitantes, famílias e casas inseridos na área rural, a área que este abrange, torna sua ocupação muito dispersa. Pelo contrário, o ambiente urbano, por sua pequena área, proporciona uma ocupação muito concentrada, embora tenha muito menos residentes.

\section{DINÂMICAS CORPORATIVAS E ASSOCIATIVAS DO GCCG: ALGUMAS}

\section{ILUSTRAÇÕES}

O tratamento sistemático das atas dos vários órgãos do Grémio - Direção, Assembleia Geral e Conselho Geral - é essencial para a compreensão de seu funcionamento e gestão e, também, da natureza e intensidade da articulação com o Estado corporativo.

A multiplicidade de questões expressadas em ata mostra a forte dependência do GCCG relativamente ao Delegado do Instituto Nacional do Trabalho e Previdência (INTP), o vínculo com a estrutura corporativa, com a função de supervisão sobre a organização corporativa e de qual provinha orientação que o GCCG era forçado a seguir (questões contratuais do pessoal do Grémio, informações sobre documentos de contabilidade, fiscalização sobre os estabelecimentos comerciais, etc.). Esta dependência é visível nos contatos regulares que os 
dirigentes do Grémio eram obrigados a realizar com a delegação de Braga do INTP, quer pela aprovação das contas, pela realização de eleições ou ainda por questões mais simples, como a realização de um chã-dançante. Ainda assim, existem várias questões de gerenciamento interno que passavam pela gestão da Direção: estatutos; eleições; contabilidade; sócios; delegados; empregados; obras; compras/vendas; beneficência; regulamentações e deliberações várias; e questões relacionadas aos membros diretivos. Era responsabilidade da Direção articular suas intenções com o desígnio da delegação do INTP e, por vezes, com a orientação do Subsecretário de Estado/Ministro das Corporações e Previdência Social.

Isto é exemplificado pelas medidas tomadas para aprovar os Estatutos, que ocorreram entre agosto de 1939 e abril de 1940. De acordo com os preparativos do Grémio, a data de 17 de agosto foi estabelecida para aprovação superior dos estatutos propostos, o que se mostrou impossível em visão do incumprimento dos organismos de supervisão e da duração do processo. Neste contexto, apesar do cumprimento formal dos prazos pelo Grémio, em particular através do envio de cópias dos estatutos para aprovação superior, por meio do delegado do INTP em Braga, a aprovação superior foi um longo processo, de acordo com as informações contidas no Livro de Atas da Comissão Organizadora e Comissão Diretiva n. ${ }^{\circ} 1$. Somente após os contatos de alguns membros do Grémio com o delegado do INTP e duas visitas ao Subsecretário de Estado das Corporações e Previdência Social em Lisboa, foi possível concretizar a aprovação, em abril de 1940 (TORRES, 2013, pp. 34 e 35).

O caso mais grave desta subordinação, no entanto, ocorreu aquando da impugnação da Direção eleita pelo delegado INTP, acompanhada da nomeação de uma comissão administrativa que governou o Grémio por quase três anos (GCCG, 1952), entre julho de 1964 e março 1967 (TORRES, 2013, p. 38).

Outra área de articulação com a estrutura corporativa se fazia através dos contatos estabelecidos com organizações similares (grémios do comércio) e com a Federação dos Grémios do Comércio de Braga e Viana do Castelo para troca de informações de natureza vária, para apoiar reivindicações avançadas por algum desses organismos ou simplesmente para a divulgação de festividades locais em que os grémios do comércio se envolviam. Igualmente expressiva é a conexão com o Sindicato Nacional dos Caixeiros do Distrito de Braga, secção de Guimarães (um organismo corporativo primário que congrega os varejistas da região administrativa do Grémio do Comércio de Guimarães). Os contatos são frequentes, motivados por questões relacionadas com os contratos de trabalho ou por mudanças no horário de trabalho, em ocasiões festivas. 
A questão dos acordos de negociação coletiva merece atenção. Entre 1939 e 1969, dois destes contratos foram assinados, em 1944 e 1963. A redação de ambos os contratos é muito semelhante, regulando a admissão, demissão, salário ou férias dos trabalhadores, bem como as relações entre estes e os empregadores. Mesmo assim, a assinatura desses contratos não era simples, dando origem a queixas dos visados, intensas trocas de impressões e grandes sessões de negociação, muitas vezes forçando à intervenção do Delegado distrital do INTP.

Também com a Fundação Nacional para a Alegria no Trabalho, se dão contatos devido à provisão de espaços para fins recreativos. Há também, embora em números escassos, conflitos jurisdicionais. Exemplo disso é o episódio entre o GCCG e o Grémio de Retalhistas de Mercearia do Norte (GRMN), na sequência do Decreto-Lei n. ${ }^{o}$ 29912, que define o registro de todas as mercearias do município no GRMN. O GCCG não aceita o legislado, tentando impedir a sua entrada em vigor. O conflito seria resolvido com a assinatura de um acordo provisório em 1941, sob a autoridade do Delegado distrital do INTP (GCCG, 1939, fl. 22).

O GCCG mostra um envolvimento na política nacional através da participação nas comemorações do regime, bem como em homenagens a figuras nacionais e locais. Exemplos disso foram o compromisso com o $40^{\circ}$ aniversário da Revolução Nacional, o protesto contra o ataque da União Indiana à província de Dadrá na década de 1950, ou a representação do Grémio na "excursão dos Organismos Corporativos do Distrito de Braga à Exposição do Mundo Português" (GCCG, 1940, fl. 19). Há também saudações recorrentes ou felicitações a elementos do poder, especialmente às figuras máximas do regime (Presidente do Conselho e Presidentes da República).

A intervenção no campo econômico, particularmente na área do comércio, é o campo privilegiado de intervenção do GCCG. Isso se manifesta em vários níveis: o organismo intervém através de vários regulamentos visando a prática do comércio (horários e preços, principalmente), manifesta apoio a empresas locais, mas também insiste na defesa de classe, contestando mesmo decisões governamentais (aumento de impostos) ou intervindo junto de entidades oficiais com pedidos específicos. Um dos principais campos de batalha do Grémio como muitos outros organismos congêneres - é a luta contra a venda ambulante, considerada altamente prejudicial ao comércio varejista estabelecido e que motivou várias iniciativas para seu controle e erradicação. Esta questão foi discutida em várias sessões da Direção e da Assembleia Geral ao longo de duas décadas (entre fevereiro de 1950 e junho de 1968), com este tipo de comércio sendo visto como desleal, já que tendeiros e ambulantes não atendiam às horas de trabalho nem respeitavam os lugares de venda. O setor é muito exigente nesta questão, 
e apresenta numerosas queixas e petições. Ao longo do tempo, como uma tentativa de combater este tipo de comércio, várias propostas são apresentadas para o controle e até mesmo a exclusão deste comércio, na cidade e no município, usando várias entidades oficiais, como a Câmara, a GNR, a Secção das Finanças local, a Delegação do INTP de Braga e até particulares.

O GCCG também desempenha um papel importante no racionamento que marca a década de 1940, uma consequência do conflito global que se travava então e das suas implicações para a economia portuguesa, uma vez que muitos dos bens essenciais para o funcionamento e satisfação de atividades e necessidades básicas (indústria, agricultura, transportes) eram adquiridos nas colônias ou no exterior, bens cuja oferta diminuiu drasticamente. Em 1941, as reservas de diversos artigos começam a se esgotar, originando a inflação, o açambarcamento, o mercado negro e o contrabando. O racionamento entrou em vigor no final de 1943. Em Guimarães, seus serviços são instalados na secretaria do GCCG, sendo transferidos para uma dependência independente devido ao volume de serviço, se mantendo em funcionamento até muito depois de terminada a guerra. O GCCG está envolvido nesta questão, principalmente buscando resolver situações de escassez de matéria-prima junto das entidades locais (Câmara Municipal, Governo Civil ou Intendência Geral de Abastecimentos).

Finalmente, a presença do GCCG na vida da cidade deve ser destacada, dinamizando três linhas a resumir o que está abaixo.

A intervenção do Grémio no município de Guimarães não se limita aos aspectos econômicos. Além de sempre procurar o progresso da cidade e do concelho, sempre cuidando, quando necessário, junto das entidades competentes para a melhoria de vários serviços (correios, ferrovias), o organismo expressa seu contentamento às principais fugiras do regime, enviando agradecimentos após decisões favoráveis a Guimarães, como a implementação do Regimento de Cavalaria 6, o que nunca aconteceria. Em alguns casos, o próprio Grémio interveio diretamente, assinando petições ou contribuindo com somas monetárias (caso do envio de $20 \$ 00$ à Comissão de Angariação de Fundos para as obras de urbanização da Capela de S. Jorge).

O organismo também tem um forte lado cultural e recreativo na cidade. Em primeiro lugar por seu papel nas Festas Gualterianas, as festas do município, relançadas no início do século pela antiga associação comercial. O Grémio colaborou com os comitês encarregados de sua organização (cedendo espaços e concedendo subsídios) e esteve mesmo, por alguns anos, na liderança de sua organização. Uma das principais atribuições do organismo foi a realização 
de um concurso de montras, realizado anualmente a partir de 1964. O Grémio dinamiza também algumas iniciativas de natureza cultural, nomeadamente, duas conferências, uma das quais, subordinada à indústria têxtil de algodão, que registra uma grande participação de comerciantes e industriais. Tenta também incentivar as comemorações do milênio da fundação do Mosteiro da Mumadona, mas sem sucesso.

Sua sede é, em várias ocasiões, o palco de exposições e conferências, para as quais o organismo contribui, cedendo o espaço para sua realização. Os espaços exteriores da sede também são usados para eventos esportivos, no entanto, nestes casos, o organismo impõe algumas condições, exigindo, por exemplo, do Grupo Esportivo Francisco de Holanda, um dos principais utilizadores do espaço, uma renda mensal e algumas garantias.

Além disso, o organismo dinamiza vários relacionamentos com associações e entidades municipais - sendo os mais privilegiados a Câmara Municipal e a Associação de Socorros Mútuos Artística Vimaranense - marcando presença no Conselho Municipal e, em várias ocasiões, se associando a cerimônias funerárias de indivíduos conectados diretamente ou indiretamente ao Grémio e à extinta Associação Comercial, ou de ilustres da cidade.

\section{OS SÓCIOS DO GCCG: UMA CARACTERIZAÇÃO}

Nos seus Estatutos, aprovados por alvará do Subsecretário de Estado das Corporações e Previdência Social, de 20 de abril de $1940^{8}$, o Grémio define duas categorias de sócios: efetivos e auxiliares.

De acordo com o artigo $9^{\circ}$ do Capítulo II dos Estatutos, o estatuto de sócio efetivo é atribuído a "empresas singulares ou coletivas que exerçam o comércio de retalho e não estejam representadas por outro grémio de ramo diferente" (GCCG, 1940, p. 8). Estas eram obrigadas a cumprir certas condições: propriedade de estabelecimento próprio e estar coletado pela contribuição industrial (art. ${ }^{\circ} 2^{\circ}$ ); apresentação de uma proposta de admissão, por escrito, à Direção; entre outros.

Os sócios efetivos estavam obrigados a cumprir uma série de deveres estabelecidos no artigo $10 .^{\circ}$ : respeito das decisões dos órgãos administrativos (a); pagamento de joias e cotas ${ }^{9}$

\footnotetext{
${ }^{8}$ Os sócios auxiliares, cuja admissão depende apenas da Direção, permanecem até 1946, desaparecendo até 1951 na sequência de um despacho do Subsecretário de Estado das Corporações e Previdência Social, que retira a aprovação ao disposto nos Estatutos sobre a admissão desses sócios. Em 1951, a categoria reaparece, se mantendo até 1956. Esses - 50 - sócios não têm relevância para o tecido comercial do município.

${ }^{9}$ Estavam isentos, ao abrigo do Decreto-Lei n. ${ }^{\circ}$ 29232, do pagamento de joia os sócios (efetivos ou auxiliares) que proviessem de qualquer Associação Patronal ou Grémio criados ao abrigo dos decretos n. ${ }^{\text {os }} 23049$ e 24715 .
} 
(b); desempenho dos cargos para os quais fossem eleitos (c); entre outros. De acordo com o artigo $12 .^{\circ}$, perdiam seu estatuto: se provado que, no curso da sua atividade, a praticavam de má fé ou cometessem fraude (a); por difamação da Organização Corporativa ou de qualquer organismo/agente vinculado a ela (b); quando sujeitos à pena de eliminação (c); quando declarassem falência $(\mathrm{d})^{10}$ ou celebrassem acordos com seus credores por menos de $50 \%$ de seu passivo (f); sendo suspensos (perdiam seu estatuto somente durante o período de suspensão) (e); ou pelo não pagamento de cotas por três meses consecutivos (g). O incumprimento das regras dos Estatutos e das deliberações dos órgãos diretivos conduziam a penalidades, que incluam censura, multas (variando entre $10 \$ 00$ e 500\$00), suspensão e eliminação ${ }^{11}$. O sócio tinha a oportunidade de apresentar sua defesa, a ser avaliada pela Direção ou pelo CG, cuja decisão era apresentada dentro de um prazo máximo de 15 dias.

Os livros de registro dos sócios do GCCG consultados apresentam 4817 sócios efetivos, permitindo analisar vários aspectos relacionados com os agremiados: contexto geográfico (rural/urbano); grupos de atividade; e itinerário associativo. Por razões de economia de texto, serão mencionadas as principais conclusões a serem extraídas dos diferentes vetores.

O itinerário associativo é analisado sob três prismas: entradas, equilíbrio do movimento associativo e duração média de permanência ${ }^{12}$. Relativamente ao primeiro, o número de novos associados mais que duplicou (de 436 entradas para 1180), com uma quebra mínima (76 associados) na década seguinte.

O equilíbrio do movimento associativo resulta do cruzamento entre as datas de entrada e saída. A análise dos dados disponíveis mostra que o equilíbrio do movimento é francamente positivo, mantendo um crescimento constante ao longo do período de estudo, partindo de um saldo de +298 no final da primeira década, para alcançar um saldo de +734 durante a década de 60.

O cruzamento das datas de entrada e saída dos associados também permite uma estimativa do tempo em que os sócios permanecem ligados ao organismo, embora de forma aproximada. Assim, com base nas informações efetivamente disponíveis, é possível concluir que a maioria dos membros estaria vinculado ao Grémio por um período de até cinco anos

\footnotetext{
${ }^{10} \mathrm{O}$ sócio que declarasse falência poderia voltar a adquirir seu estatuto de sócio desde que provasse estar reabilitado por sentença judicial.

${ }^{11}$ As penalizações de censura, multa e suspensão eram da responsabilidade do Conselho Geral, com a pena da eliminação a ser da competência da Direção.

${ }^{12}$ A saída dos sócios também era uma hipótese a considerar, no entanto, uma vez que a informação neste campo se encontra muito incompleta, esta hipótese foi abandonada. Uma vez que a informação relativa à saída e entrada de sócios se encontra incompleta, a análise do itinerário associativo representa um cálculo meramente aproximativo.
} 
(485), muitos deles saindo durante ou após o primeiro ano (221). A partir dos cinco anos, e até 20 anos ou mais de permanência, o número de associados diminui gradualmente. No entanto, é possível determinar a existência de associados que estiveram vinculados ao organismo por mais de 20 anos (destes, a grande maioria excede mesmo o período de vida do Grémio, com a data de demissão referente ao encerramento de atividade, já no século XXI).

\section{CARACTERIZAÇÃO DO TECIDO COMERCIAL VIMARANENSE}

O tecido comercial se caracteriza sob três prismas: contexto geográfico, ramo de atividade e dimensão econômica.

A distribuição dos agremiados pelo meio rural versus ambiente urbano, de acordo com a localização administrativa das freguesias, é essencial para conhecimento do universo dos associados e a natureza de intervenção do GCCG no município. 70\% dos associados inscritos se localizam em freguesias rurais face aos $29 \%$ que residem em freguesias urbanas. O cálculo das densidades comerciais revela uma discrepância assinalável: nas áreas rurais, a densidade comercial é de $13,7 \mathrm{com} / \mathrm{km}^{2}$, em contraste com a densidade urbana de $1042,4 \mathrm{com} / \mathrm{km}^{2}$.

Os ramos do comércio foram agrupados de acordo com o tipo de atividade exercida, o que resultou na criação de 10 classes distribuídas da seguinte forma: Grupo I - Vestuário, Têxtil e Calçado; Grupo II - Géneros alimentícios; Grupo III - Drogaria e Ferragens; Grupo IV Agentes/Comissários; Grupo V - Eletricidade/Aparelhos Domésticos; Grupo VI - Móveis e similares; Grupo VII - Couros; Grupo VIII - Papelaria; Grupo IX - Quinquilharias; e o Grupo $\mathrm{X}$ - Comércio não especificado. 
Gráfico I - Distribuição dos estabelecimentos de acordo com a classificação dos grupos comerciais, entre 1939 e 1969

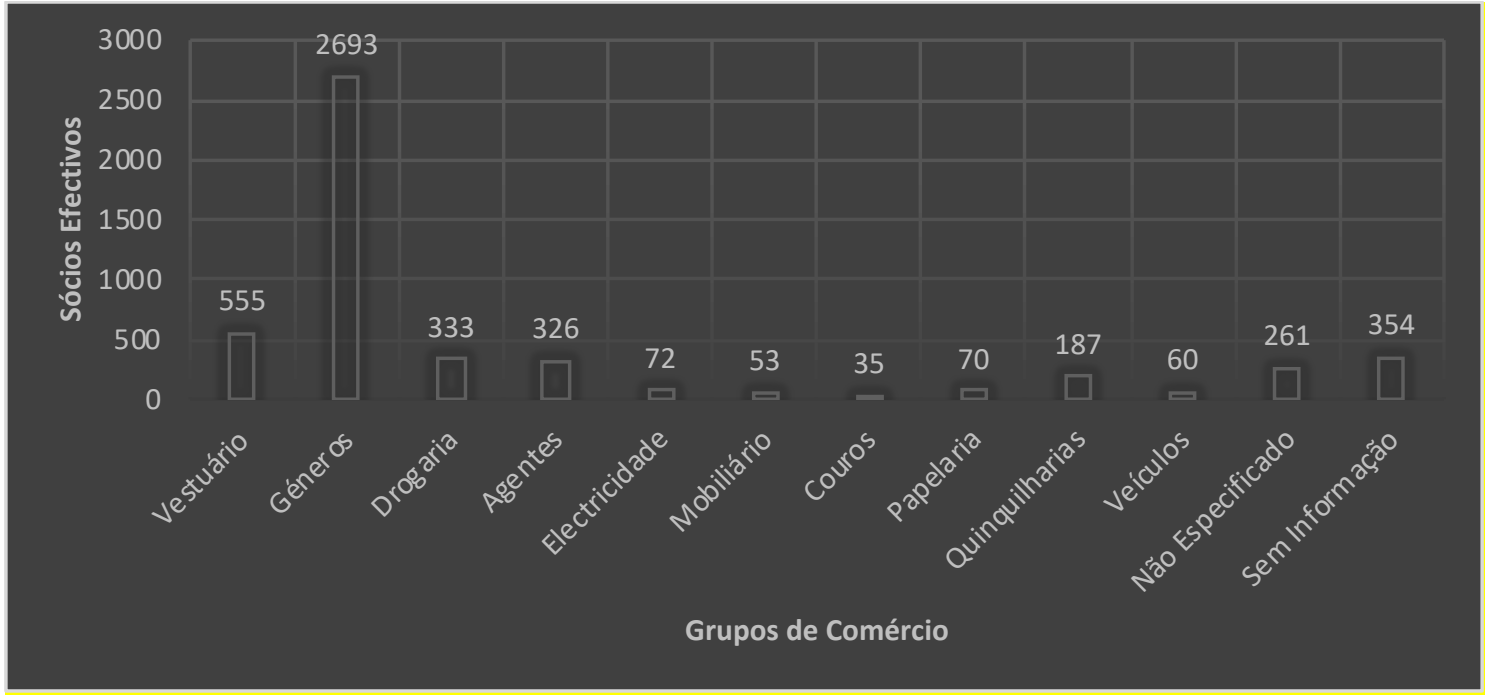

Como pode ser visto no gráfico I (TORRES, 2013), o setor predominante é o setor alimentar, grupo II, que representa 54\% do universo em análise (2693 registros). A certa distância, surge o grupo Vestuário, têxteis e calçado, grupo I, com 13\% (535) dos estabelecimentos. Correspondente a um terceiro se encontram os grupos Drogaria e Ferragens, Agentes/Comissários e Comércio não especificado, representando 7\% (333), 6\% (326) e 5\% (261) dos comerciantes registrados ${ }^{13}$.

Como ilustração, a análise do grupo II revela que é neste grupo que existe uma maior diversidade de negócios, contando-se oito subgrupos. Vale a pena mencionar as mercearias (976), representando $36 \%$ de todo o grupo; além do comércio de bebidas, que representa $32 \%$ do grupo (891 comerciantes/estabelecimentos, cuja grande maioria se dedica à venda de bebidas alcoólicas). Os outros subgrupos dizem respeito ao comércio de: vegetais; carnes e derivados; peixe e marisco; padaria e confeitaria; restauração; existindo ainda um subgrupo cujos produtos não se encaixam nos anteriores.

\footnotetext{
13 Os restantes grupos apresentam valores residuais, não ultrapassando os $10 \%$, percentagem que resulta das percentagens setoriais: os grupos de Eletricidade/Aparelhos Domésticos (72) e Quinquilharias (187) representam apenas $2 \%$ cada, e por fim, com $1 \%$ os grupos do Mobiliário e Similares (53), Couros (35) e Papelaria (70).
}

Oficina do Historiador, Porto Alegre, EDIPUCRS, v. 11, n. 2, jul./dez. 2018, 
Mapa II - Evolução temporal do grupo de comércio II, Géneros alimentícios
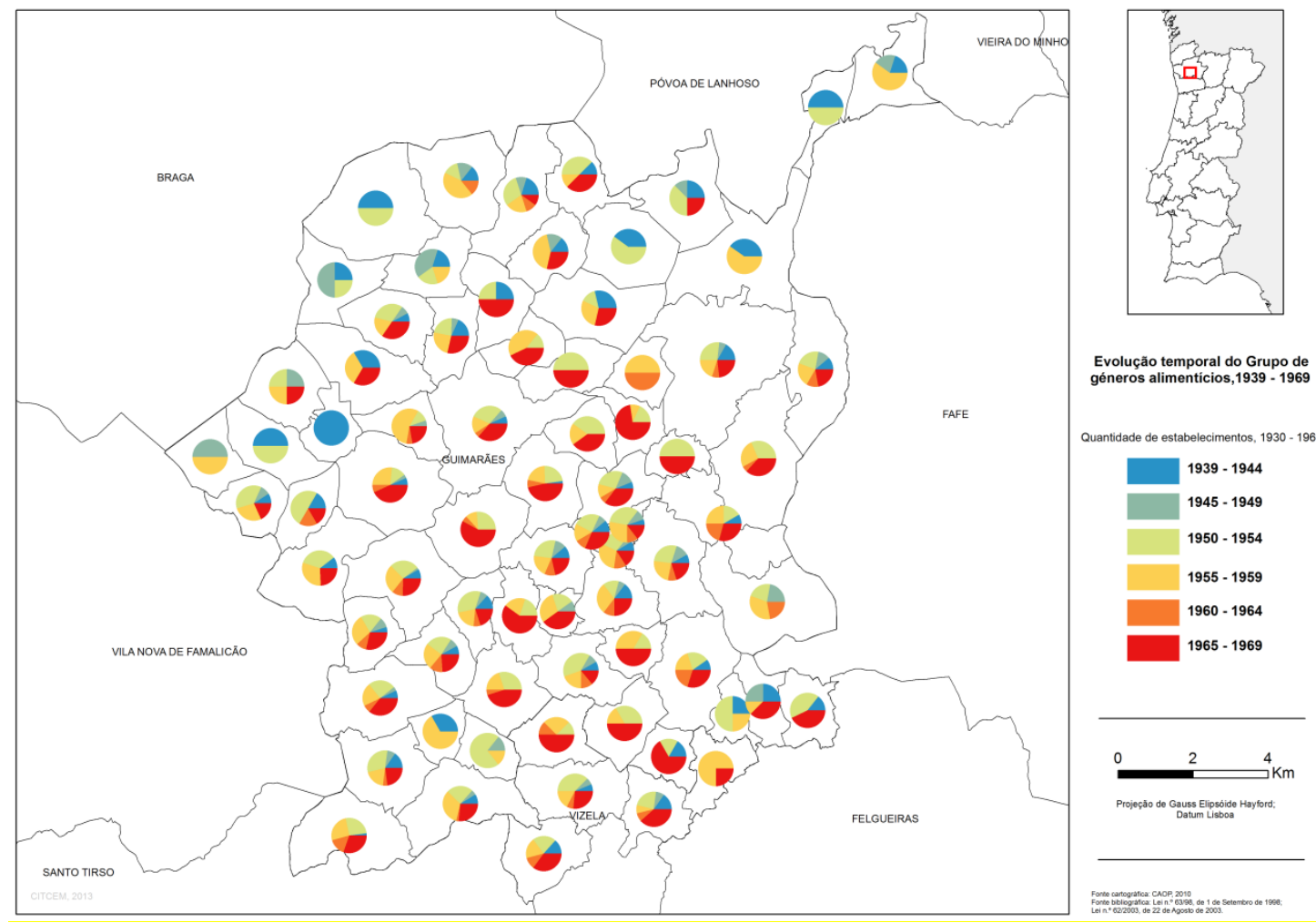

O Mapa II ilustra a presença de associadas conectados a este grupo comercial por freguesia do município vimaranense, em intervalos de cinco anos, entre 1939 e 1969, a fim de determinar os períodos em que há mais entradas de associados neste grupo. $\mathrm{Na}$ zona mais periférica ao norte do município, a maioria dos estabelecimentos deste grupo de comércio, surgem entre 1940 e 1954. No restante concelho, com exceção de casos ocasionais, há uma distribuição mais equitativa, com maior inclinação para o período entre 1965 e 1969.

Os livros de registro de cobranças do Grémio, disponíveis apenas para o período entre 1940 e 1959, nos permitem avaliar a importância econômica dos associados e de seus negócios. O valor da quota a que os sócios efetivos estavam sujeitos corresponde "a 1 por milhar sobre o lucro tributável atribuído para efeito da contribuição industrial paga ao Estado, arredondada em escudos" (GCCG, 1940, p. 11), variando de uma cota mínima de $2 \$ 50$ e uma máxima de $30 \$ 00^{14}$.

\footnotetext{
${ }^{14}$ No total existiam 31 escalões: o mais baixo no valor de $2 \$ 50$, o escalão seguinte era o de $3 \$ 00$, sendo que a partir daqui os escalões aumentam um escudo cada até se chegar aos $30 \$ 00$ (em duas ocasiões surgem ainda dois escalões que não mais se repetem: $7 \$ 50$ e $27 \$ 50$ ).
} 
Entre 1940 e 1959 foram pagas 17351 quotas mensais, gerando um valor total de 943997\$50. Durante o período em análise, o comportamento do número e valor das cotas mostra tendências diferentes.

Gráfico II - Evolução do número de contribuintes efetivos registrados no GCCG, 1940-1959

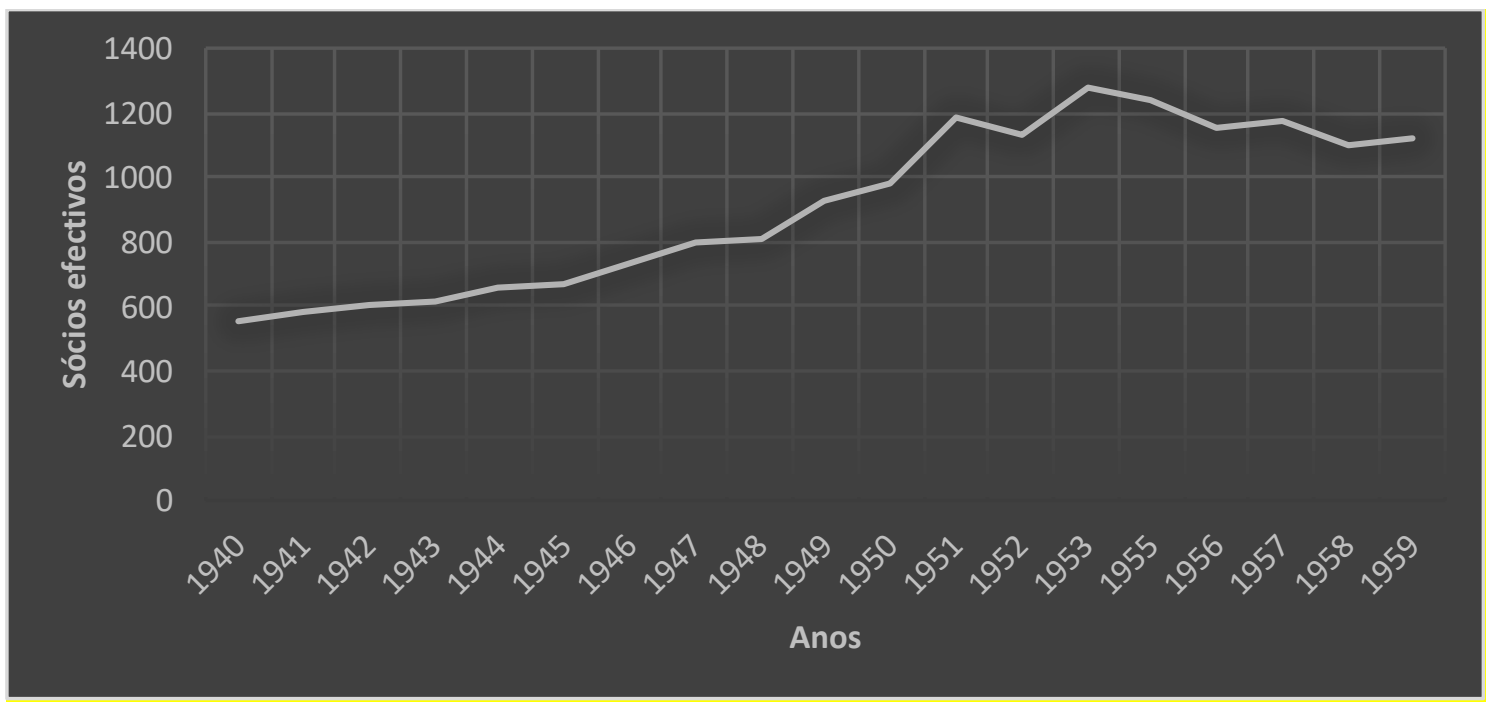

Analisando o Gráfico II (TORRES, 2013), há um aumento gradual, com o número de contribuintes aumentando de forma segura entre 1940 e 1951, de 555 para 1181 sócios pagantes. No ano seguinte, houve uma ligeira queda, atingindo seu pico em 1953, com 1278 contribuintes. A partir deste ano, o número de contribuintes diminui, embora esteja intercalado com pequenas recuperações, terminando o período em estudo, com 1120 sócios efetivos a pagar cotas. 
Gráfico III - Evolução dos valores de cobrança dos efetivos registrados no GCCG, 1940-1959

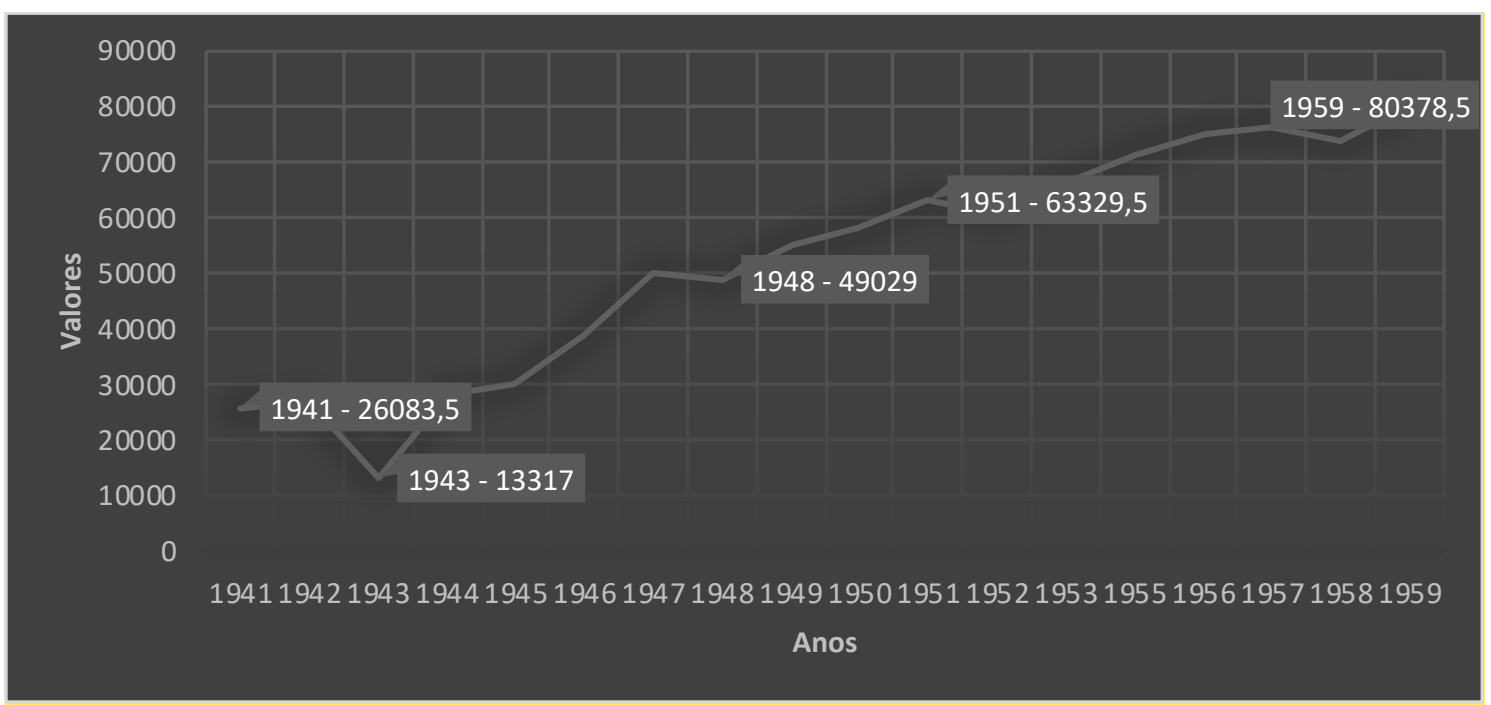

Em relação aos valores obtidos anualmente através da coleta das cotas, visível no gráfico III (TORRES, 2013), há um aumento constante entre 1941 (não há valores para 1940) e 1959, embora com três períodos de interrupção (não superior a um ano) ${ }^{15}$. Assim, em 1941, o valor anual era de $26083 \$ 50$, e no último ano em que tal informação existe, 1959, o total anual foi de $80378 \$ 50$, uma soma maior do que a registrada no ano de 1941 em aproximadamente $68 \%$. Além disso, o ano de 1959 é mesmo o ano em que o Grémio obtém maior receita com a coleta de cotas aos sócios efetivos.

A referência cruzada desta informação com os grupos de comércio permite identificar os setores economicamente mais poderosos, os grupos relacionados com o setor têxtil e a eletricidade. É nestes grupos que encontramos os contribuintes que pagam os escalões de quotização mais elevados. Curiosamente, nestes grupos, a distribuição rural/urbano não é muito significativa. Por sua vez, o grupo economicamente menos lucrativo é o dos Móveis e similares: a maioria dos seus contribuintes paga as cotas nos níveis escalões mais baixos. Do mesmo modo, o setor alimentar é também dos menos rentáveis: as cotas pagas se situam, sobretudo, entre $2 \$ 50$ e $10 \$ 00$, embora os contribuintes desse setor representem $88 \%$ do total dos sócios.

Além dos sócios efetivos, o GCCG conta ainda com contribuintes que não possuem estatuto de sócio. Estes são contribuintes, que figuram no registro de quotização, como consequência do Decreto-Lei n. ${ }^{\circ} 29931$, de setembro de 1939, que obriga todas as empresas exercendo atividades em ramos de comércio e indústria organizadas corporativamente - a pagar

\footnotetext{
${ }^{15}$ A única excepção é o ano de 1943, que regista o valor anual mais baixo em todo o período em análise, apenas $13317 \$ 00$, no entanto, este ano é excepcional, uma vez que todos os escalões sofrem um corte de $50 \%$ no valor total anual, em relação ao que era normalmente cobrado.
} 
as joias e cotas previstas para os sócios desses organismos corporativos. No total, existem 1737 indivíduos na situação de não-inscritos, resultando em 3932 cotas pagas. Em relação a este grupo, as informações recolhidas são insuficientes e não há indicações sobre o campo de atividade ou as datas de entrada/saída, se encontrando as informações relativas ao endereço incompletas.

Dado este conjunto de informações, é possível verificar que o comércio de vimaranense deste período era principalmente um comércio pequeno, rural e pobre, direcionado ao consumo local, com uma oferta diversificada de produtos, principalmente gêneros alimentícios, têxteis e vestuário, alimentado por uma economia de satisfação das necessidades mais primárias, num contexto de uma economia rural marcada pela importância de algumas empresas industriais e uma rede de pequenas oficinas.

O GCCG estabeleceu um novo curso para os desígnios da ACIG, afastando-se da defesa do comércio e da indústria e de seus associados, mudando sua estrutura associativa para seguir a orientação política imposta pelo Estado Novo. O Grémio integra o sistema corporativo, como elemento base, dependendo do regime político, sob a orientação direta do delegado distrital do INTP. O sistema corporativo exigiu a manutenção regular de contatos com outros organismos congêneres e superiores, para troca de informações, manifestações de suporte ou, no caso dos organismos superiores, para fazer cumprir as diretrizes impostas.

Em sua área de atuação, a área econômica, o GCCG desempenhou um papel importante, através dos regulamentos impostos à prática comercial, mas também na defesa da classe, apelando a entidades oficiais ou contestando decisões governamentais. No entanto, "a intervenção do GCCG no concelho de Guimarães não se limitou a aspectos econômicos. Além de procurar sempre o progresso da cidade do concelho, diligenciando sempre que necessário junto das entidades competentes para o melhoramento de vários serviços (correios, caminhosde-ferro, entre outros), o organismo expressa o seu contentamento às principais figuras de regime, enviando agradecimentos depois de decisões favoráveis a Guimarães” (Torres, 2013, p. 129). Além disso, o organismo tinha também um forte lado cultural e recreativo junto da cidade, participando das festas municipais, autorizando a realização de vários eventos em sua sede associativa e até mesmo tentando dinamizar eventos.

Apesar do concelho vimaranense ser descrito pelo delegado distrital do INTP como "o principal centro de vida corporativa e de trabalho deste Distrito" (INTP Braga, 1940), sendo o GCCG o mais relevante em número de associados e de valores movimentados (no início dos anos 40) vindo a perder essa posição para o Grémio do Comércio de Braga (cuja área 
administrativa era muito superior), o delegado não tece palavras muito elogiosas em relação aos grémios do comércio e ao grémio vimaranense. Do GCCG, destaca a sua sede num "magnifico prédio que ostenta tradições muito queridas às gentes de Guimarães" (INTP Braga, 1943), afirmando que o organismo "não tem obra, nem peito para ela" (INTP Braga, 1943), atuando de forma muito semelhante ao Grémio bracarense, marcado por uma resistência passiva ao novo regime, não se mostrando interessado num acordo com os sindicatos do distrito para a convenção de trabalho.

Com a Revolução do 25 de Abril o Estado Novo cai e a estrutura corporativa, uma de suas bases, é de imediatamente questionada.

A primeira reação do Grémio do Comércio vimaranense à nova situação política ocorre em uma reunião da Direção, convocada extraordinariamente, em 30 de abril, com a aprovação do envio de um telegrama para a Junta de Salvação Nacional expressando o apoio incondicional do organismo. Na mesma reunião, também foi decidido enviar uma carta ao Delegado da Junta no Ministério das Corporações solicitando a convocação de eleições livres.

Poucos dias depois, no dia sete de maio, ocorre a última reunião da Direção do Grémio do Comércio do Concelho de Guimarães. Em uma sessão extraordinária, o Presidente explicou o desejo de um grupo de comerciantes de realizar uma reunião de trabalho com o objetivo de apresentar suas demandas, se expressando o pleno apoio da Direção. Nesta sessão, e como última deliberação deste órgão diretivo, foi decidido convocar uma Assembleia Magna para propor uma Comissão Eleitoral. Em dois de dezembro, a Assembleia Geral da Associação Comercial de Guimarães se reúne pela primeira vez, e em 25 de fevereiro de 1976, os primeiros dirigentes desta nova Associação são eleitos.

\section{REFERÊNCIAS BIBLIOGRÁFICAS}

BASTOS, Carlos. Livro de Ouro do Comércio e da Indústria de Portugal. Porto: Edição do Autor, 1957.

CAL, Alexandre Herculano. Legislação Corporativa. Grémios do Comércio e da Indústria e Sindicatos. Porto: Edição do Autor, 1955.

CARDOSO, José Luís. Corporativismo, Instituições Políticas e Desempenho Económico. In ROSAS, Fernando; GARRIDO, Álvaro (coord.). Corporativismo, Fascismos, Estado Novo. Coimbra: Edições Almedina, 2012, p. 101-120. 
FREIRE, Dulce; ESTEVÃO FERREIRA, Nuno; RODRIGUES, Ana Margarida.

Corporativismo e Estado Novo. Contributo para um roteiro de arquivos das instituições corporativas. Lisboa: ICS, 2014.

GAGLIARDI, Alessio. Il Corporativismo Fascista. Bari: Gius, Laterza \& Fligi, 2010.

GARRIDO, Álvaro. Contexto, fundamentos e lógicas de construção da economia nacional corporativa. In ROSAS, Fernando; GARRIDO, Álvaro (coord.). Corporativismo,

Fascismos, Estado Novo. Coimbra: Edições Almedina, 2012, p. 143-164.

GRÉMIO DO COMÉRCIO DO CONCELHO DE GUIMARÃES. Estatutos. Barcelos: Companhia Editora do Minho, 1940.

LUCENA, Manuel. A Evolução do Sistema Corporativo Português, 2 vols. Lisboa:

Perspectiva \& Realidade, 1976.

ROSAS, Fernando; GARRIDO, Álvaro (coord.). Corporativismo, Fascismos, Estado Novo. Coimbra: Edições Almedina, 2012.

ROSAS, Fernando. Salazar e o Poder, A Arte de Saber Durar. Lisboa: Tinta da China, 2013.

\section{FONTES}

Instituto Nacional do Trabalho e Previdência Delegação de Braga (INTP Braga). Relatório 1940.

INTP Braga, Relatório 1942.

INTP Braga, Relatório 1. semestre 1943.

INTP Braga, Relatório 2. ${ }^{\circ}$ semestre 1943.

INTP Braga, Relatório 1947.

INTP Braga, Relatório 1948.

INTP Braga, Relatório 1949.

Grémio do Comércio do Concelho de Guimarães (GCCG). Actas da Assembleia Geral, 1944 a 1967;

GCCG, Actas da Comissão Organizadora e comissão directiva $n .{ }^{\circ} 1,1939$ a 1942. 
GCCG. Actas da Direcção e da comissão adjunta referente à organização e realização das festas da cidade, 1956 a 1957 ;

GCCG. Actas da Direcção $n .^{\circ}$ 2, 1942 a 1952;

GCCG. Actas da Direcção $n .^{\circ}$ 3, 1952 a 1969;

GCCG. Actas de posse, 1937 a 1938;

GCCG. Actas do Conselho Geral n. ${ }^{\circ}$ 1, 1942 a 1962;

GCCG. Cobrança rural, 1942-1950;

GCCG. Cobrança urbana, 1942-1951;

GCCG. Descarga de cotas, 1953 a 1955;

GCCG. Folha de cobrança do mês, 1956;

GCCG. Folha de cobrança rural, $1958-1959$;

GCCG. Folha de cobrança urbana, 1958-1959;

GCCG. Livro de cotização urbana, 1945;

GCCG. Mapas de cobrança, 1957;

GCCG. Registo da cobrança e conta corrente dos sócios e empresas colectadas no 20 semestre, 1940;

GCCG. Registo da cobrança urbana, 1941;

GCCG. Registo das empresas comerciais cotizadoras, 1939 a 1940;

GCCG. Registo de cobrança e conta corrente das empresas cotizadoras, 1940;

GCCG. Registo de cobrança rural, 1941;

GCCG. Registo de sócios auxiliares, 1940 a 1946;

GCCG. Registo de sócios efectivos, 1939 a 1970; 
GCCG. Registo de sócios, 1848 a 1970;

GCCG. Registo de sócios, 1950 a 1956;

GCCG. Registo de sócios, 1968 a 1970.

ARTIGO ENVIADO EM: 07/02/2017

ARTIGO ACEITO PARA PUBLICAÇÃO EM: 01/08/2017

Oficina do Historiador, Porto Alegre, EDIPUCRS, v. 11, n. 2, jul./dez. 2018, 